\title{
My course is a series, and what is yours?
}

\section{Jutta Pauschenwein ${ }^{1}$, Wolfgang Kühnelt ${ }^{2}$, Edith Podhovnik ${ }^{2}$}

${ }^{1}$ ZML-Innovative Learning Scenarios, FH JOANNEUM, Austria ${ }^{2}$ Journalism and Public Relations, FH JOANNEUM, Austria.

\begin{abstract}
Everybody is talking about the newest episodes on Netflix, Amazon Prime or other channels. While the cultural phenomen of a "series" is nothing new, it has never been so popular as today. The "lockdown" era brought more streaming, more time at home and more online teaching. Starting with the idea that our students (and many of our teachers) are now part of the "Netflix generation", we have been integrating serial elements in education and training. This contribution describes the first experiments of using the elements of a series in teaching. Regardless of whether online and offline teaching, teachers and trainers can use some classical methods of series, such as recaps and cliffhangers, teasers and mysteries to make the courses not only more interesting but also more consistent. Encouraged by the positive results of our experiments, we will be taking the series a step further in the upcoming semester and include elements of an interactive series in our teaching. Together with the students, we will be developing a storyboard outlining the series' episodes throughout the semester.
\end{abstract}

Keywords: Learning; series; online; interactive; training; teaching. 


\section{Introduction}

In today's entertainment industry, the series plays an important part. The subscription numbers of the streaming service Netflix are rising, and Amazon, Apple and others are becoming more involved in the entertainment business. But the idea of series is much older - and its basic principles are by no means only usable for the entertainment industry.

Many students and adult learners belong to the "Netflix generation". Regardless of whether young or old, people enjoy watching and discussing their favorite series. The streaming platform Netflix reported almost a quarter more revenue in the first quarter of 2020, thanks to an increase in paying subscribers and had more than 203 million subscribers in the forth quarter of 2020.

When people talk about series in teaching, they usually integrate existing (TV) series into their course, as scenes from Dr. House in medical studies or telenovelas in language classes. In this paper, we focus at implementing serial elements in training and teaching. After briefly discussing the background and existing research on series, we describe our first experiments of how elements of a series can be used in teaching and training.
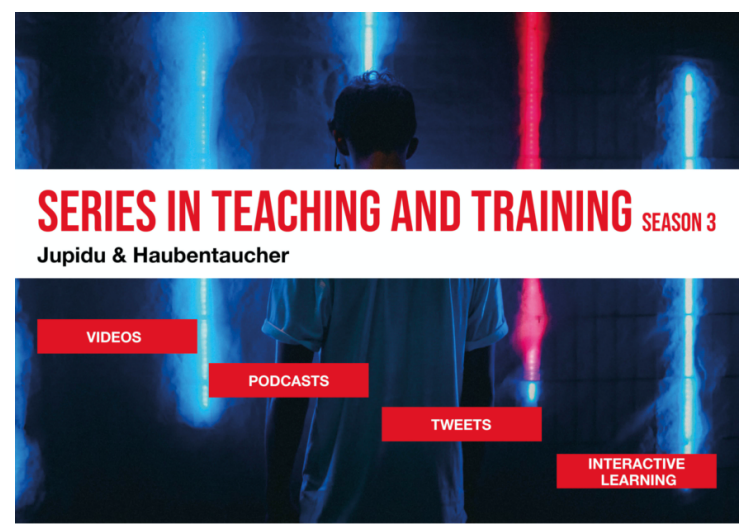

Figure 1. background picture: unsplash.com / Chester Wade, text by the authors

\subsection{Background and research}

Christian Blümelhuber (2011), lecturer on strategic corporate communication at the Berlin University of the Arts, defines a series as the variation of the same thing over and over again. Like a brand which offers security and orientation to consumers, a series helps the audience to find their way through the jungle of entertainment products. From Episode 1 of a series onwards, the audience is meeting familiar people and is recognising patterns in the plot as storytelling is inherent in films and series.

Many teachers and trainers, too, are increasingly relying on stories to foster learning as our memory stores a story faster and more efficiently than facts. A story triggers emotions, which 
in turn stimulate deeper learning processes (Masemann, 2009). Research refers to this as episodic memory (Radvansky, 2015). We deduce that, in teaching and training, the learners are better in remembering content placed along a clearly outlined story arc than classically presented learning material. Lugmayr et al (2017) use the name "serious storytelling" in this context.

Additionally, a historical model for series in the classroom exists. From the 1960s until the end of the 1990s school television offered for example mathematics and Russian in Germany and Austria (Barth, 1978). Print media, too, uses elements of series as the media repeat certain formats in regular intervals (Knellessen, Schiesser and Strassberg, 2015).

To find out more about the phenomenon of a series, we have conducted four interviews, namely with Wolfgang Temmel (2020), Florian Born (2020), Jana Burbach (2020) as well as Stefan Zinke (2020), and have received recommendations from the training institution Serial Eyes in Berlin (2019). Wolfgang Temmel is a multimedia artist from Austria. The Austrian Florian Born works in Agile Management and Software Development (Born, 2020) and is an avid recipient of podcasts. These comparatively new digital formats often have a fixed protagonist, a given topic and guests. Jana Burbach (2020) and Stefan Zinke (2020) are series authors from Germany.

\section{What defines a series?}

A series has several episodes arranged in seasons. There is a clear dramaturgy with acting characters as well as a clear "branding" with name, graphics, sound, tonality and more. A series has fixed elements that are repeated in each episode and on the other hand there are new aspects of the story in each episode. Series are not new. On the contrary, Umberto Eco has identified serial thinking in the work of Shakespeare and in Star Wars and refers to 1980s as the "age of repetition". (Eco, 1987, p. 50)

\subsection{Elements of a series and a connection to teaching and training}

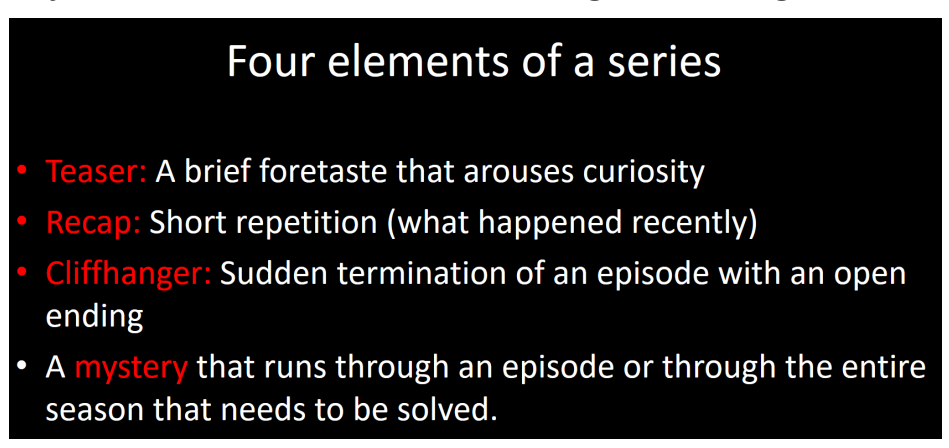

Figure 2. Elements of a series - own illustration 
The four elements of a series - teaser, recap, cliffhanger and mystery - can be applied to teaching and training. As shown in Fig. 2, the teaser invites the audience to watch the episode or listen to the podcast. In teaching or training, the teaser refers to the syllabus or the workshop description functions as the teaser. The recap of a series can be easily applied to the start of a class. Instructors as well as students can recap on what happened in the last class - or episode. While it might be difficult to imagine a cliffhanger in the classroom, it is possible to include this element. Mysteries, on the other hand, are easy to incorporate because learning is all about solving mysteries. The learning experience can be enhanced with multimedia products, such as videos, blogs, and podcasts.

\subsection{What is the benefit of a series in the classroom?}

Teaching and training can benefit from the series as the series provides orientation. It ensures continuity for teachers/trainers and students/learners as it offers a relatively fixed setting and a story arc over a longer period of time. Ideally, the classroom series also creates tension with its elements of cliffhangers and mysteries as it makes students wonder what will happen next.

\section{Case studies}

The integration of serial elements into our teaching started in March 2020. In the two semesters of 2020 and 2020/21, we applied the approach of a series to different areas, in online training and online teaching for example with videos and podcasts.

\subsection{Elements of series in the master's programme}

In the master's programme "Media Competence and Digital Literacy", video interviews were incorporated as a series. Four video interviews were created on the topic of "Social Media in the Cultural Sector". To illustrate the series character, the video interviews were provided with a specific graphic line. The videos were made available to the master's students on an online platform to be used in the asynchronous part of the course.

\subsection{A series for train the trainer/teacher}

The online women's network \#dienetzwerkerinnen has been created for women to empower and support each other in their everyday professional lives and explore ways to help shape the digital transformation. In the network, women work on their current projects in a moderated exchange process, whereby creative and visual approaches to solutions are an essential part of the process. Due to the COVID pandemic, there was an urgent need to learn not only how to deal with technology to set up a found pedagogical framework but also how to deal with learners exclusively in an online way.

To help with pedagogy and technology, two seasons with nine episodes were created between March and August 2020 for a broad target group of trainers, teachers, and everybody else 
who was in need of learning. Season 3 started on February 26, 2021. The series with the name \#didaktischekleinigkeiten - \#didactictrivia-comprised topics such as video reflection, visual online collaboration, moderation of the online group, concepts for online trainings, the quality of online training/teaching and others (dienetzwerkerinnen, 2020).

In the first season, two episodes were created each week. After an evaluation among the online readers, the episodes of the second season were created weekly. The episodes were posted on a website. Photos, self-drawn comics, audio podcasts with a length of three to five minutes, and sometimes videos were included.

\section{The power of Comics!}

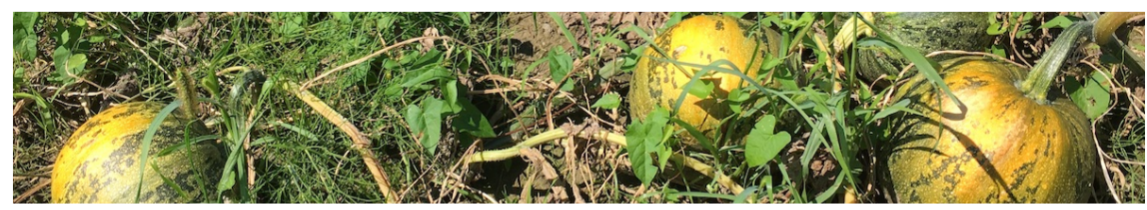

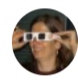

jupidu

August 6, 2020

\#didaktischekleinigkeiten

Comics, Matt Silady, Nick

Sousanis, Online-

Workshop, Raum \& Zeit,

Staffel2
Dies ist die neunte und letzte Episode von Staffel 2 in der Serie Didaktische Kleinigkeiten zum Thema Comics. Danach gibt es für die Serie einmal Sommerpause. Wenn Sie die nächsten Beiträge der \#netzwerkerinnen nicht verpassen möchten, abonnieren Sie unseren Blog!

Worum geht es?

Figure 3. Episode 9, season 2, series \#didaktischekleinigkeiten-screenshot

Each episode has the same structure, starting with a short teaser and answering the questions of what the topic is and how we solve the dilemma. Each episode finished with a checklist for teachers and trainers and offered additional material.

\subsection{Workshops}

In two workshops with teachers and trainers in 2020 and 2021, we discussed the possibilities, risks and chances of using serial elements in teaching.

\subsection{A series in the bachelor's programme Journalism and Public Relations (PR)}

In the course "Web competences in communication-related professions" during the winter semester of $2020 / 21$, the students translate theory into practise by using the social media platform Twitter. The semester is divided into four phases where the students tweet in 
continuity and acquire deeper skills. Accrodingly, the series \#twitterpraxis consists of four episodes guiding the students through the semester.

\section{jupidu @jupidu.Nov 2, 2020}

Guten Morgen, liebe \#jpr20 Studierende - mit diesem Podcast eröffne ich Phase 1: Schreiben/ Tweeten/ Twittern/ Zwitschern der \#twitterpraxis \#episode2 \#serie - Textinfos finden sich im Kurs in \#moodle oer.fhjoanneum.at/zml/wp-content...
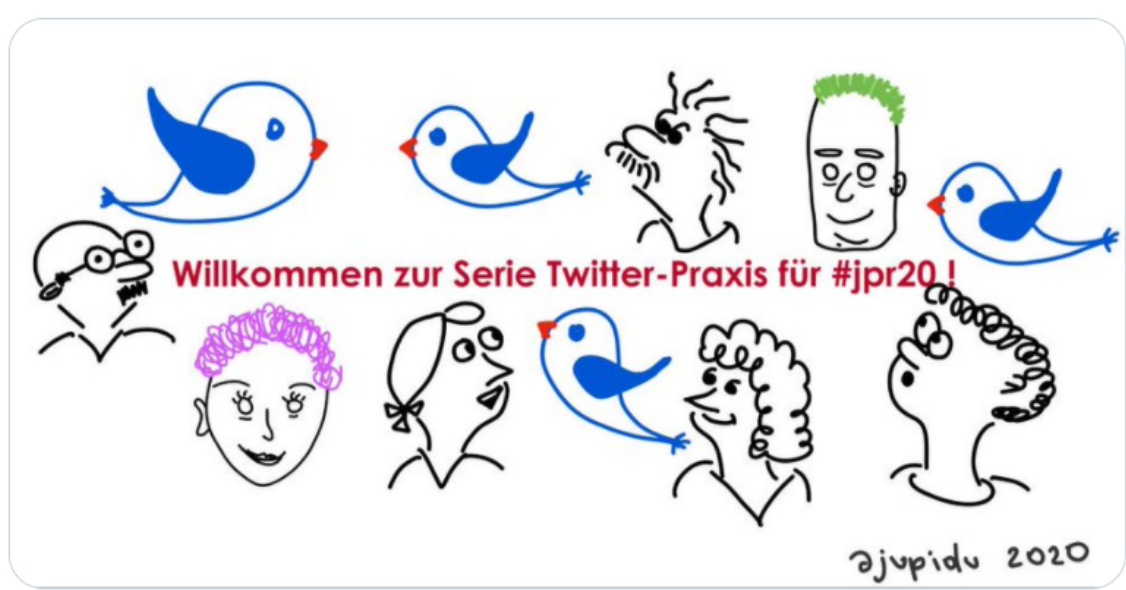

Figure 4. Twitter-Series by jupidu-screenshot

The first episode was implemented as a video, which was already used in the year before and only had to be adapted to the idea of a series. The other three episodes were created as audio podcasts of about three to four minutes and shared with the students in Twitter (Pauschenwein, 2020). The content focused on the new tasks and on increasing the competence of the students.

\section{Discussion and Outlook}

By moderately inserting elements of the series, we give the audience in our teaching events, workshops and trainings a better orientation about the planned activities and increase the excitement for all participants including teachers and trainers.

To evaluate the use of series in learning scenarios, it is necessary to analyze the results obtained and reflect on the process. Starting with a series, developing multimedial materials for the episodes and making it available for learners on a continuous basis takes a lot of work. While we did not systematically analyze how learning happened in classes and in the network, we established some spaces for reflection and feedback. The potential and challenge of series in class were discussed several times with university teachers during workshops and 
at conferences. In developing the series for the use in the classroom, we reflected upon what worked, what was difficult and what should be changed. Additionally, we discussed possible future developments.

The first season of the series \#didaktischekleinigkeiten - \#didactictrivia - was evaluated in an online questionnaire and two interviews. We also asked the students about the series in class as well. The students seem to like it and stayed engaged during the difficult COVIDsemesters. Yet, we did not see better grades with this pedagogical approach. We are planning on collecting quantitative data to validate our approach, possibly in an international cooperation.

Our next step is to develop an interactive series with the students or training participants. At the beginning of a new semester, we are planning to construct a storyboard together that will guide us through the following months. This interaction will increase the intrinsic motivation for the students to follow the course and to play a more active role.

\section{Acknowledgements}

The project \#dienetzwerkerinnen is supported by the Austrian Research Promotion Agency (FFG) - Programme Laura Bassi/Frauen gestalten Digitalisierung (www.ffg.at).

\section{References}

Barth, N. (1978). Schulfernsehen, Effektivität und Konsequenzen für den Unterricht: Ergebnisse, Erkenntnisse und Schlußfolgerungen aus einem Großversuch in allen berufsbildenden Schulen Hessens. Beltz. Weinheim, Basel

Blümelhuber C. at TEDxKoeln (2011). Alles Serie oder was? Die 3. Idee im Marketing. Retrieved from: https://www.youtube.com/watch?v=WeRvDTVM7gY

Born, F. (2020). Wolfgang Kühnelt interviews Florian Born via Zoom on 19.3.2020

Burbach, J. (2020). Retrieved from: www.janaburbach.com

Dienetzwerkerinnen (2020). Retrieved from: https://www.dienetzwerkerinnen.at/?s=didaktische+kleinigkeiten

Eco, U. (1987). Streit der Interpretationen. Universitätsverlag Konstanz, Konstanzer Bibliothek Band 8, Serialität im Universum der Kunst und der Massenmedien, S. 49-65

Fröhlich, V. (2015). Der Cliffhanger und die serielle Narration. Analyse einer transmedialen Erzähltechnik. Transcript Edition Medienwissenschaft.

Knellessen, O., Schiesser, G., \& Strassberg, D. (2015). Serialität. Wissenschaften, Künste, Medien. Turia + Kant

Lugmayr, A., Sutinen, E., Suhonen, J., Sedano, C. I., Hlavacs, H., and Montero, C. S. (2017). Serious storytelling-a first definition and review. Multimedia tools and applications, 76(14), 15707-15733. 
Masemann, S. and Messer, B. (2009). Improvisation und Storytelling in Training und Unterricht. Beltz. Weinheim und Basel

Number of Netflix subscribers worldwide from Q3 2011 to Q4 2020 (2020). Retrieved from: https://de.statista.com/statistik/daten/studie/196642/umfrage/abonnenten-von-netflixquartalszahlen/

Pauschenwein, J (2020). Podcast, \#twitterpraxis. Retrieved February 19, 2020 from https://oer.fh-joanneum.at/zml/wpcontent/uploads/2020/10/Twitterpraxis_episode2_2020.mp3

Radvansky, G. A. (2015). Human memory. Psychology Press.

Serial Eyes (2019). Retrieved from: https://creative-europe-desk.de/artikel/2019-0328/Serial-Eyes-2019/?id=4689

Temmel, W. (2020). Wolfgang Kühnelt interviews Wolfgang Temmel on 13.6.2020

Zinke, S. G. (2020). Retrieved from: https://ifsscreenwriting.wordpress.com/stefan-gustavzinke/

zfm Zeitschrift für Medienwissenschaft Nr. 7 2/2012 „Die Serie“. Retrieved from: https://zfmedienwissenschaft.de/search/node/serie 